\title{
Will the Strength of the Clavicle Plate be Increased by Inserting Small Screws into the Empty Holes above the Fracture Site?
}

\section{Dae-Geun Kim ( $\sim$ kuroo25@schmc.ac.kr)}

Department of Orthopedic Surgery, Soonchunhyang University Gumi Hospital https://orcid.org/00000001-6355-4105

\section{Soo Min Kim}

Gumi Electronics and Information Technology Research Institute

\section{Research article}

Keywords: clavicle fracture, plate fixation, screw, finite element analysis

Posted Date: August 26th, 2020

DOl: https://doi.org/10.21203/rs.3.rs-57329/v1

License: (c) (i) This work is licensed under a Creative Commons Attribution 4.0 International License.

Read Full License 


\section{Abstract}

Background: Open reduction and plate fixation is the standard surgery for displaced midshaft clavicle fractures because of biomechanical stability. Implant failure like plate breakage or deformation is the most serious complication of plate fixation. Several plate designs for midshaft clavicle fractures have been introduced, but traditional superior plate has been mostly used.

Methods: We generated the clavicle 3D image using the computed tomography (CT) of the left normal clavicle of a 54-year-old female, and then made the comminuted midshaft clavicle fracture model with 10-mm fracture site gap. The fracture model was fixed with 7-hole superior locking compression plate. Finite element analysis (FEA) was performed between the presence (model B) and absence (model A) of screws above the fracture site.

Results: The average peak stress from the cantilever bending force was much greater than the peak stress from the axial compression and axial torsion force. This means that the cantilever loading force is the main force which could cause plate breakage or deformation. The maximal stress of the model $B$ was lower than the one of the model A. Therefore, model B showed superior biomechanical property than model A under all loading conditions, especially cantilever bending force.

Conclusions: The peak stress of the superior clavicle plate could be decreased just by inserting a small screw into the screw hole above the fracture site.

\section{Background}

Clavicle fracture is the most common trauma of the scapular girdle and occurs about $81 \%$ at the midshaft [1, 2]. Non-displaced clavicle fractures are usually managed conservatively [3, 4], but open reduction and plate fixation is the standard treatment for displaced midshaft clavicle fracture to reduce risk of shortening, nonunion, malunion and so on [5-7]. Actually, displacement and comminuted pattern are $48 \%$ and $19 \%$ in the midshaft clavicle fracture [8].

Among the surgical procedures, plate fixation provides biomechanically stable strength for early mobilization and gives good clinical outcomes $[9,10]$. Major complication associated with plate fixation is implant failure due to plate breakage or deformation. A previous study demonstrated two risk factures for plate breakage: the use of reconstruction plate and the bridging plate technique $[11,12]$.

According to the study which was a FEA about clavicle fracture fixation, the maximum stress in the precontoured superior reconstruction plate fixation without lag screws occurred at the edge of screw holes above the fracture site [13]. Also other study revealed that the weakest point of the superior clavicle locking compression plate in comminuted midshaft clavicle fracture is the screw holes above fracture zone, especially in the cantilever bending force and therefore recommended a new design which is a superior locking plate without screw holes above fracture zone to prevent metal failure [14]. However, in mass production of metal plates, it is practically impossible to remove a hole only in the fracture area. 
We considered placing small screws in the holes above the fracture area on the actual metal plate to remove empty holes and give similar effect as the previously described new design. Our hypothesis is that the strength of the plate could be increased by inserting small screws into the holes above the fracture zone in the clavicle fractures.

\section{Methods}

\section{Finite element model}

A computed tomography (CT) of the left normal clavicle of a 54-year-old female volunteer was used to generate the clavicle 3D model. The axial images were obtained with $1.0 \mathrm{~mm}$ slice thickness and then a 3D model was created by using a free medical software which is InVesalius (Center for Information Technology Renato Archer, Campinas, Brazil); the 3D model was imported into ANSYS mechanical simulation (ANSYS, Inc., Canonsburg, PA, USA) for FEA. The finite element meshes were generated as a tetrahedral $0.5 \mathrm{~mm}$ size for bones, plates, and screws. The average mesh element quality was 0.83861 and the orthogonal quality was 0.85907 . The total generated mesh nodes were $1,843,793$ EA and elements were $1,258,688$ EA.

There was 5-mm transverse gap between a medial and a lateral fragment, which means a comminuted midshaft clavicle fracture. The fracture was fixed with 7-hole superior locking plate which was modeled by a 2.5-mm, 7-hole titanium superior locking compression clavicle plate system (AO Synthes, Solothurn, Switzerland). To simplify the simulation, just locking holes were used instead of combi holes.

There were two models: one is the fracture model which was fixed with six 2.5-mm locking screws on both medial and lateral fragment without screw fixation above the fracture site (model A) ; on the other hand, a small screws was inserted to fill the empty hole, not into the bone in the other model (model B) in Figure 1.

The contact interface between all items was set as a totally bonded condition for the bone-plate interface with high contact angle, the plate-screw and screw-bone interfaces. The material properties of cortical bone, cancellous bone and titanium alloy were applied as literature references in Table 1 [15].

\section{Mechanical loading test}

Like the previous study, three common loading modes with boundary condition were applied at the lateral end of the clavicle: $100 \mathrm{~N}$ of cantilever bending, $100 \mathrm{~N}$ of axial compression and $1 \mathrm{Nm}$ of counterclockwise axial torsion for case of raise hand in Figure 2.

The stress distributions in the plate were measured on the seven points same as seven locking holes of superior clavicle plates: medial (M) 1, 2, 3, fracture site (FS), lateral (L) 1, 2, 3 in Figure 1. The peak stresses on each point and maximal stress of both plate models in all three forces were analyzed as the von Mises stress. 


\section{Results}

The von Mises stresses for each plate are shown in Table 2. In cantilever bending force, the average stress of $M 1,2,3$ and $L 1,2,3$ in the both plates are similar that average ratio $(M / L)$ is 1.108, but the stress of FS was dramatically lowered just by insertion of small screw from $1000.800 \mathrm{MPa}$ in model A to $438.560 \mathrm{MPa}$ in model $\mathrm{B}$. The peak stress point in the model A were at the FS point, and the peak stress of the model A (1027.400 MPa) was larger than one of the model B (582.050 MPa) in Figure 3. This similar trend was shown in the axial compression loading. As shown in Figure 4, the stress of FS was much lowered from $279.810 \mathrm{MPa}$ in model $\mathrm{A}$ to $123.930 \mathrm{MPa}$ in model $\mathrm{B}$, and peak stress of the model $\mathrm{A}$ (297.690 MPa) was larger than one of the model B (181.220 MPa) in Table 2. On the other hand, this tendency about the FS stress was not found in the counterclockwise axial torsion load in Figure 5 . The von Mises stress of FS point was higher even though small screw was inserted (model A: $31.100 \mathrm{MPa}$, model B: $67.845 \mathrm{MPa}$ ), but the peak stress of the model B was slightly lower than the one of the model A (model A: $131.920 \mathrm{MPa}$, model B: $127.960 \mathrm{MPa}$ ).

\section{Discussion}

The management of displaced midshaft clavicle fractures remains challenge. According to the recent meta-analysis study [7], surgical treatment for displaced clavicle fractures led to a greater possibility of union at 1 year of follow-up. Patients who hesitate to have surgery for acute displaced midshaft clavicle fractures could have the possibility of nonunion more than $10 \%$ of patients. Also, these nonunion would be more difficult to treat compared with acute fractures. Therefore, acute displaced clavicle fractures are recommended surgery to reduce risk of nonunion and malunion.

Open reduction and plate fixation are the standard surgery for displaced midshaft clavicle fractures. Plate fixation provides biomechanically stable strength for early mobilization and then are more used rather than intramedullary fixation. The holes above the fracture site are not usually filled with screws to prohibit nonunion, and just remain empty. However, implant failure is one of the complications in plate fixation. Some FEA studies recommend various type of plates such as anterior plate, spiral plate, superior plate without screws holes above fracture zone and so on [14-17].

According to the FEA comparison between superior locking plate with and without screw holes above fracture zone [14], the biomechanical property of superior clavicle locking plate without screw holes above fracture zone is superior to the standard locking plate with screw holes above fracture zone, with a significantly lower peak stress on the screw holes above fracture zone in all loading conditions. The reason why we pay attention to this study is that locking plates is the same as a manufactured superior locking plate used nowadays, so we don't need to develop a new design and set equipment for manufacture. However, it is practically impossible to remove holes only in the fracture area in mass production of clavicle superior locking plates. We wondered that if inserting small screws into an empty hole above the fracture site would have the same effect as superior locking plate without screw holes above fracture zone. 
We set a comminuted midshaft clavicle fracture model fixed with 7-hole titanium locking compression superior clavicle plate and did FEA comparison between superior clavicle plate with (model B) and without a screw (model A) above the fracture site. According to the result in Table 2, the FS stress of model A from the cantilever bending force $(1000.800 \mathrm{MPa})$ was much greater than the peak stress from the axial compression (279.810 MPa) and axial torsion force (31.100 MPa). This result means that the cantilever loading force is the force that has the greatest impact on implant failure.

The model B reduced the peak stress on the FS point with $56.179 \%$ decrease in cantilever bending force and $55.709 \%$ decrease in axial compression loading compared to the model $A$, whereas the model A's peak stress was higher approximately 1.765 times rather than the model B. Nevertheless, the maximal stress received by the superior plate under all three loading conditions was low overall in model B with screw inserted, and the biggest difference was the cantilever loading condition.

In axial torsion load condition, peak stress position was changed to another point because counterclockwise moment moved force vector to different direction in Figure 6. As shown in Figure 6, the peak stress position moved to L1 point of rear side plate, it shows same result on both models.

The study had several limitations. First, actual clavicle fracture is not as simple as the model constructed in this study and is very complex, and the number of fracture cases varies greatly in practice. Second, there's are some considerations such as micromotion between bone and plate, variation of clavicle anatomy, bone quality and quantitative and the stress riser effect of the screws. To simplify simulation, the authors excluded these considerations. Third, the magnitude of the applied forces is not reflected in the magnitude of the force actually acting in the body, but rather the relative nature of the force's direction.

Further studies will require analysis according to various form of bone and fracture. In addition to the shape of plates, studies on the location, number, size and orientation of screws will also have to be conducted simultaneously.

\section{Conclusions}

As previous studies $[13,14]$, the screw hole above the fracture site is the weakest point in the superior clavicle locking plate for comminuted midshaft clavicle fracture, especially in the cantilever bending force. B model showed superior biomechanical property than A model under all loading conditions. Therefore, we can reduce the peak stress using a small screw insertion into the screw hole above the fracture site.

\section{Abbreviations}

CT: Computed Tomography

FEA: Finite Element Analysis 
M: medial; FS: fracture site; L: lateral

\section{Declarations}

\section{Ethics approval and consent to participate}

This study was conducted following approval by the Institutional Review Board of Soonchunhyang University Gumi Hospital and the written informed consent of volunteers has been obtained.

\section{Consent for publication}

Not applicable.

\section{Availability of data and materials}

The data analyzed during the current study are available from the corresponding author on reasonable request.

\section{Competing interests}

The authors have no conflict of interest to disclose.

\section{Funding}

Not applicable.

\section{Authors' contributions}

Kim DG contributed to the conception and design of the study, and was a major contributor in writing the manuscript. Kim SM analyzed and interpreted numerical calculation and 3D modeling. All authors read and approved the final manuscript.

\section{Acknowledgements}

This research was supported by the Soonchunhyang University Research Fund.

\section{Author details}

${ }^{1}$ Department of Orthopedic Surgery, College of Medicine, Soonchunhyang University Gumi Hospital, Gumi, Korea

${ }^{2}$ Convergence Material Research Center, Innovative Technology Research Division, Gumi Electronics and Information Technology Research Institute (GERI), Gumi, Korea

\section{ORCID}


Soo Min Kim https://orcid.org/0000-0002-9144-7355

\section{References}

1. Nordqvist A, Petersson C: The incidence of fractures of the clavicle. Clin Orthop Relat Res 1994(300):127-132.

2. Robinson CM: Fractures of the clavicle in the adult. Epidemiology and classification. $J$ Bone Joint Surg Br1998, 80(3):476-484.

3. van der Meijden OA, Gaskill TR, Millett PJ: Treatment of clavicle fractures: current concepts review. $J$ Shoulder Elbow Surg 2012, 21(3):423-429.

4. Lazarides S, Zafiropoulos G: Conservative treatment of fractures at the middle third of the clavicle: the relevance of shortening and clinical outcome. J Shoulder Elbow Surg 2006, 15(2):191-194.

5. Xie L, Ding F, Zhao Z, Chen Y, Xing D: Operative versus non-operative treatment in complex proximal humeral fractures: a meta-analysis of randomized controlled trials. Springerplus 2015, 4:728.

6. Zlowodzki M, Zelle BA, Cole PA, Jeray K, McKee MD, Evidence-Based Orthopaedic Trauma Working G: Treatment of acute midshaft clavicle fractures: systematic review of $\mathbf{2 1 4 4}$ fractures: on behalf of the Evidence-Based Orthopaedic Trauma Working Group. J Orthop Trauma 2005, 19(7):504-507.

7. Axelrod DE, Ekhtiari S, Bozzo A, Bhandari M, Johal H: What Is the Best Evidence for Management of Displaced Midshaft Clavicle Fractures? A Systematic Review and Network Meta-analysis of 22 Randomized Controlled Trials. Clin Orthop Relat Res 2020, 478(2):392-402.

8. Postacchini F, Gumina S, De Santis P, Albo F: Epidemiology of clavicle fractures. J Shoulder Elbow Surg 2002, 11(5):452-456.

9. Nourian A, Dhaliwal S, Vangala S, Vezeridis PS: Midshaft Fractures of the Clavicle: A Meta-analysis Comparing Surgical Fixation Using Anteroinferior Plating Versus Superior Plating. J Orthop Trauma 2017, 31(9):461-467.

10. Woltz S, Krijnen P, Schipper IB: Plate Fixation Versus Nonoperative Treatment for Displaced Midshaft Clavicular Fractures: A Meta-Analysis of Randomized Controlled Trials. J Bone Joint Surg Am 2017, 99(12):1051-1057.

11. Iannotti MR, Crosby LA, Stafford P, Grayson G, Goulet R: Effects of plate location and selection on the stability of midshaft clavicle osteotomies: a biomechanical study. J Shoulder Elbow Surg 2002, 11(5):457-462.

12. Meeuwis MA, Pull Ter Gunne AF, Verhofstad MH, van der Heijden FH: Construct failure after open reduction and plate fixation of displaced midshaft clavicular fractures. Injury 2017, 48(3):715-719.

13. Marie $\mathrm{C}$ : Strength analysis of clavicle fracture fixation devices and fixation techniques using finite element analysis with musculoskeletal force input. Med Biol Eng Comput 2015, 53(8):759-769. 
14. Pengrung N, Lakdee N, Puncreobutr C, Lohwongwatana B, Sa-Ngasoongsong P: Finite element analysis comparison between superior clavicle locking plate with and without screw holes above fracture zone in midshaft clavicular fracture. BMC Musculoskelet Disord 2019, 20(1):465.

15. Zhang F, Chen F, Qi Y, Qian Z, Ni S, Zhong Z, Zhang X, Li D, Yu B: Finite element analysis of dual small plate fixation and single plate fixation for treatment of midshaft clavicle fractures. J Orthop Surg Res 2020, 15(1):148.

16. Huang TL, Chen WC, Lin KJ, Tsai CL, Lin KP, Wei HW: Conceptual finite element study for comparison among superior, anterior, and spiral clavicle plate fixations for midshaft clavicle fracture. Med Eng Phys 2016, 38(10):1070-1075.

17. Zhang X, Cheng X, Yin B, Wang J, Li S, Liu G, Hu Z, Wu W, Zhang Y: Finite element analysis of spiral plate and Herbert screw fixation for treatment of midshaft clavicle fractures. Medicine (Baltimore) 2019, 98(34):e16898.

\section{Tables}

Table 1. Material properties adopted in numerical simulation models

\begin{tabular}{|llllll|}
\hline Materials & $\begin{array}{l}\text { Young's modulus } \\
{[\mathrm{MPa}]}\end{array}$ & $\begin{array}{l}\text { Poisson's } \\
\text { ratio }\end{array}$ & $\begin{array}{l}\text { Density } \\
{[\mathrm{g} / \mathrm{cm} 3]}\end{array}$ & $\begin{array}{l}\text { Bulk modulus } \\
{[\mathrm{MPa}]}\end{array}$ & $\begin{array}{l}\text { Shear modulus } \\
{[\mathrm{MPa}]}\end{array}$ \\
\hline Cortical bone & 17,000 & 0.3 & 1.19 & 14,167 & 6,539 \\
\hline $\begin{array}{l}\text { Cancellous } \\
\text { bone }\end{array}$ & 1,000 & 0.3 & 1.19 & 833 & 385 \\
\hline $\begin{array}{l}\text { Titanium } \\
\text { alloy }\end{array}$ & 186,400 & 0.3 & 4.62 & 155,330 & 71,692 \\
\hline
\end{tabular}




\begin{tabular}{|c|c|c|c|c|c|c|}
\hline \multirow[t]{2}{*}{ Points } & \multicolumn{2}{|c|}{$\begin{array}{l}\text { Cantilever bending load } \\
\text { [MPa] }\end{array}$} & \multicolumn{2}{|c|}{$\begin{array}{l}\text { Axial compression load } \\
\text { [MPa] }\end{array}$} & \multicolumn{2}{|c|}{$\begin{array}{l}\text { Axial torsion load } \\
{[\mathrm{MPa}]}\end{array}$} \\
\hline & Model A & Model B & Model A & Model B & Model A & Model B \\
\hline M1 & 22.228 & 22.268 & 1.633 & 1.641 & 7.204 & 7.222 \\
\hline M2 & 47.740 & 47.827 & 7.698 & 7.721 & 16.494 & 16.539 \\
\hline M3 & 131.550 & 131.410 & 32.535 & 32.492 & 35.413 & 35.451 \\
\hline FS & 1000.800 & 438.560 & 279.810 & 123.930 & 31.100 & 67.845 \\
\hline L1 & 104.790 & 104.430 & 32.844 & 32.725 & 45.499 & 45.526 \\
\hline L2 & 50.685 & 50.761 & 15.660 & 15.684 & 34.420 & 34.461 \\
\hline L3 & 26.453 & 26.378 & 8.255 & 8.233 & 15.758 & 15.769 \\
\hline Average $\mathrm{M}$ & 67.173 & 67.168 & 13.955 & 13.951 & 19.704 & 19.737 \\
\hline Average L & 60.643 & 60.523 & 18.920 & 18.881 & 31.892 & 31.919 \\
\hline $\begin{array}{l}\text { Average ratio } \\
(M / L)\end{array}$ & 1.108 & 1.110 & 0.738 & 0.739 & 0.618 & 0.618 \\
\hline Maximum & 1027.400 & 582.050 & 297.690 & 181.220 & 131.920 & 127.960 \\
\hline
\end{tabular}

* M: medial, FS: fracture site, L: lateral

\section{Figures}
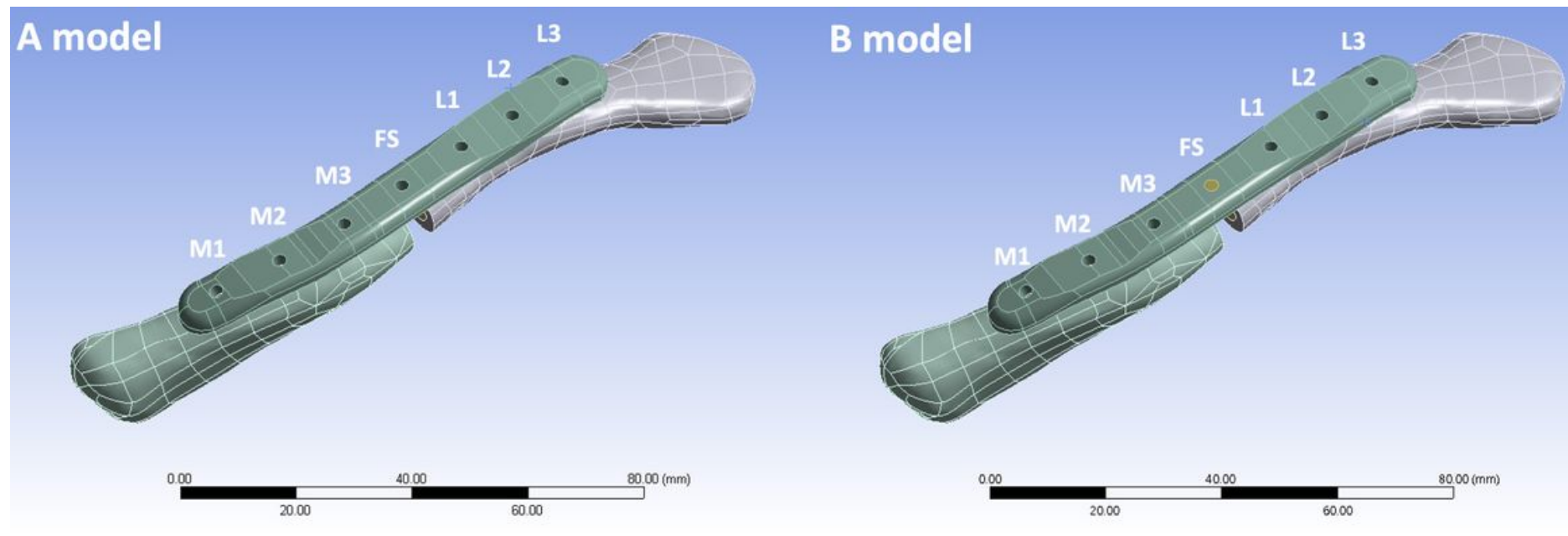


\section{Figure 1}

Simulation model structure (left) A model: FS point bolt missing, (right) B model: All bolts contact
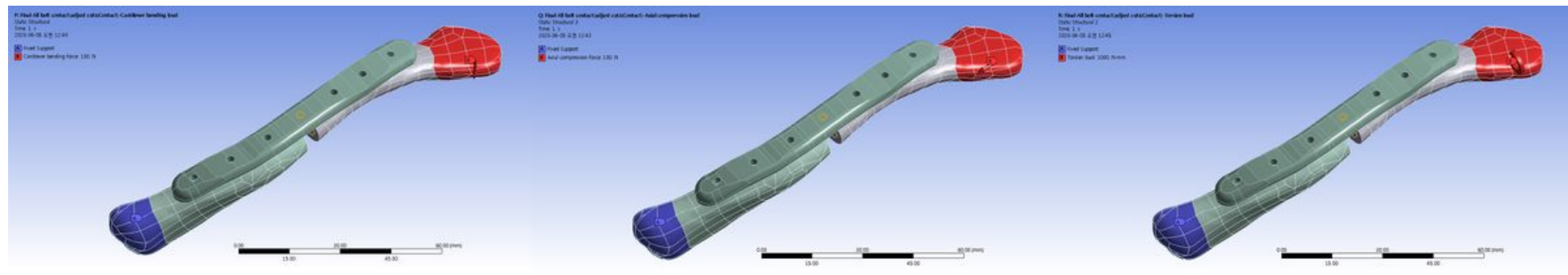

\section{Figure 2}

Boundary conditions of clavicle simulation model, (left) cantilever bending load, (mid) axial compression load, (right) axial torsion load with count clockwise

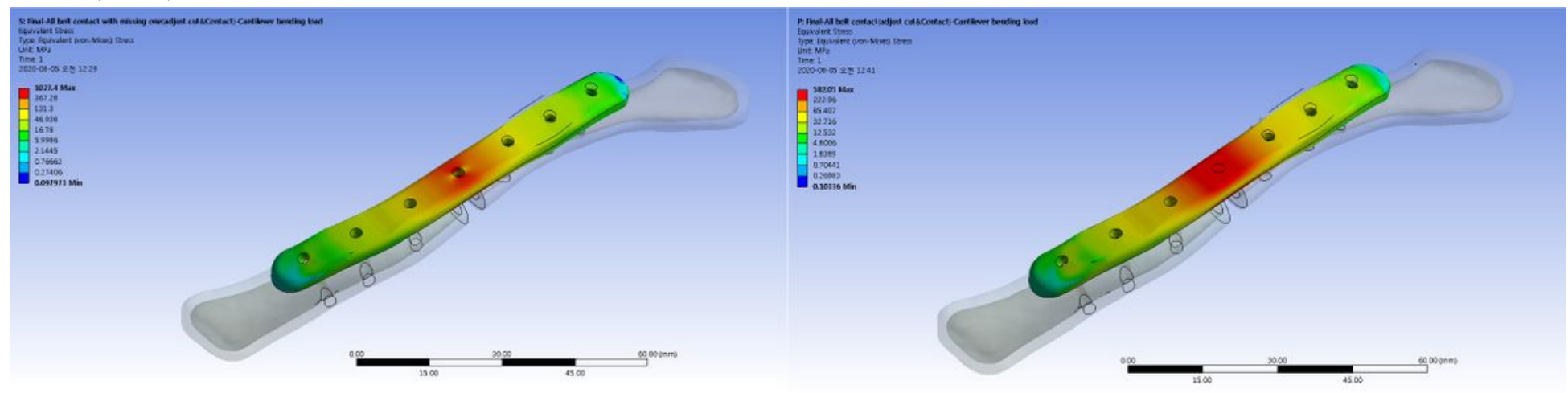

\section{Figure 3}

Von Mises stress distribution of cantilever bending load condition, (left) A model, (right) B model

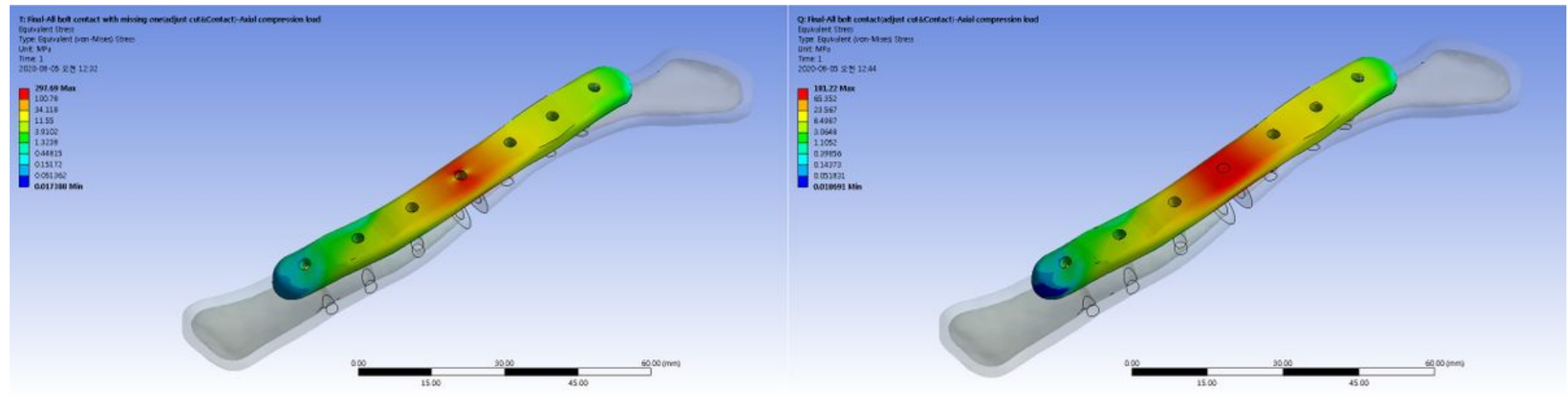

\section{Figure 4}

Von Mises stress distribution of axial compression load condition, (left) A model, (right) B model 


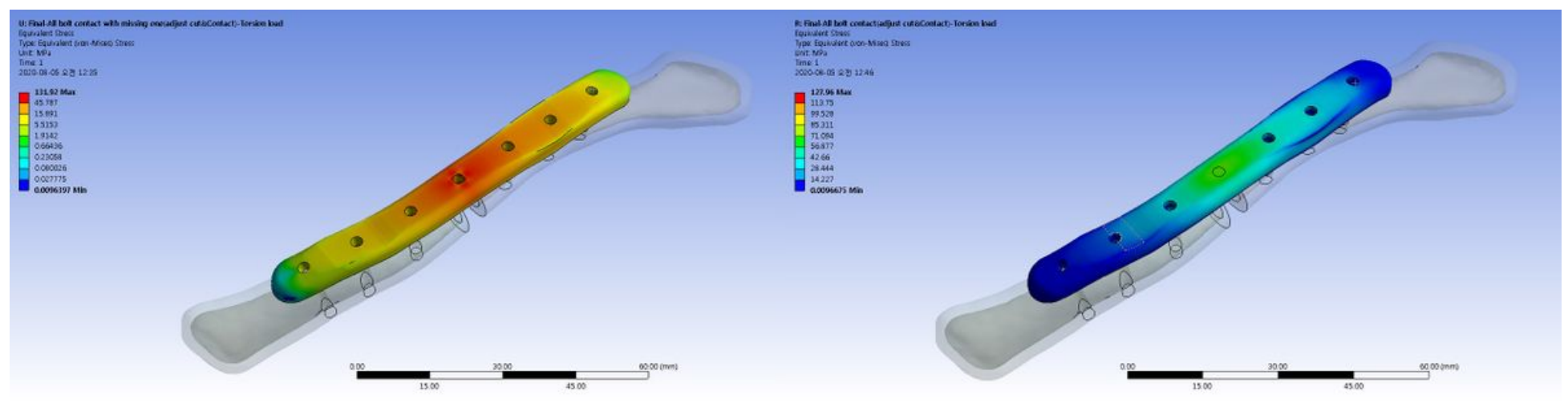

\section{Figure 5}

Von Mises stress distribution of axial torsion load condition, (left) A model, (right) B model

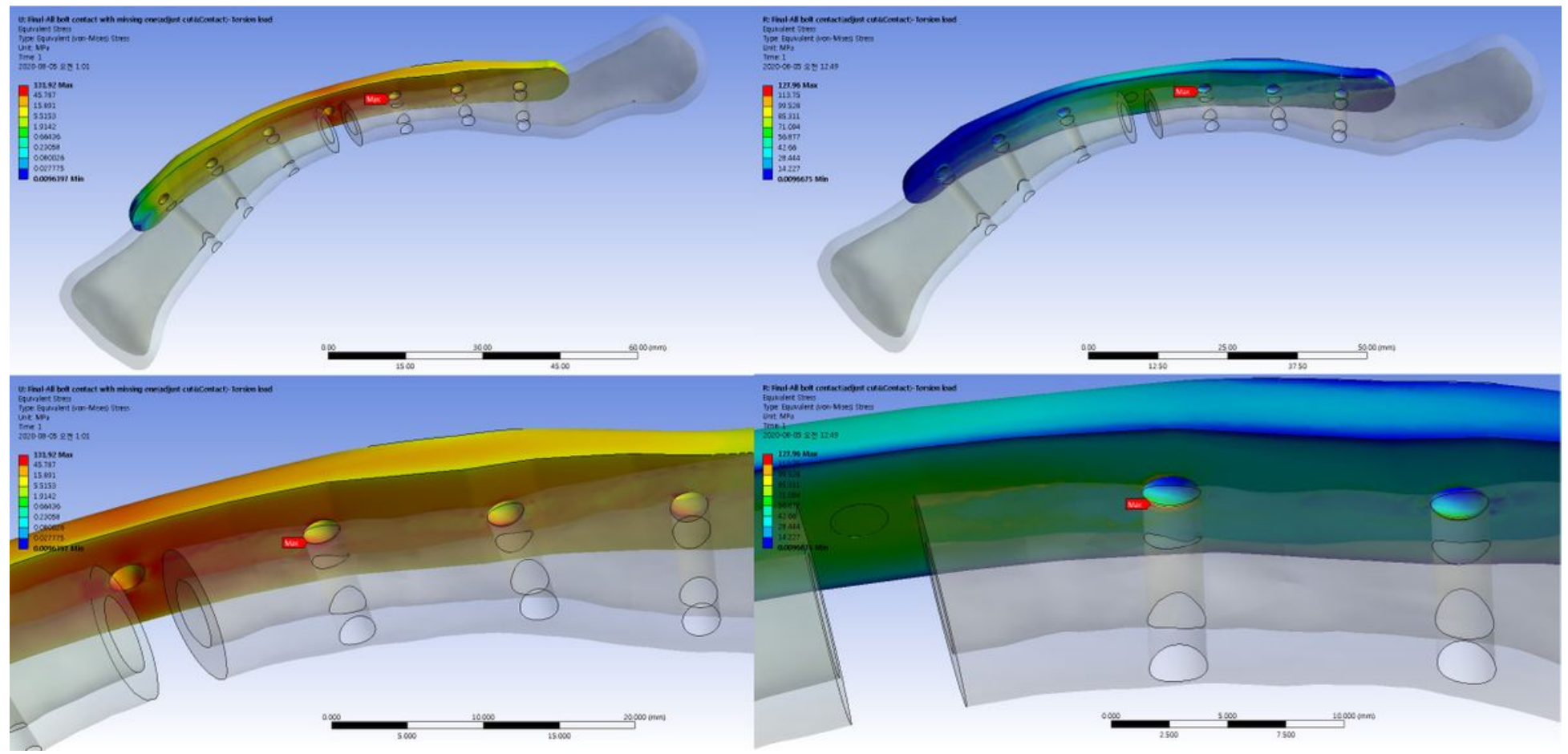

Figure 6

Von Mises stress distribution of axial torsion load condition at maximum peak stress position, (up-left) A model, (down-left) enlarge A model, (up-right) B model, (down-right) enlarge B model 